\title{
TU/e Emonowe

\section{Quantitative analysis of bone reactions to relative motions at implant-bone interfaces}

Citation for published version (APA):

Weinans, H., Huiskes, H. W. J., \& Grootenboer, H. J. (1993). Quantitative analysis of bone reactions to relative motions at implant-bone interfaces. Journal of Biomechanics, 26(11), 1271-1281. https://doi.org/10.1016/00219290(93)90351-E

DOI:

10.1016/0021-9290(93)90351-E

Document status and date:

Published: 01/01/1993

\section{Document Version:}

Publisher's PDF, also known as Version of Record (includes final page, issue and volume numbers)

\section{Please check the document version of this publication:}

- A submitted manuscript is the version of the article upon submission and before peer-review. There can be important differences between the submitted version and the official published version of record. People interested in the research are advised to contact the author for the final version of the publication, or visit the $\mathrm{DOI}$ to the publisher's website.

- The final author version and the galley proof are versions of the publication after peer review.

- The final published version features the final layout of the paper including the volume, issue and page numbers.

Link to publication

\section{General rights}

Copyright and moral rights for the publications made accessible in the public portal are retained by the authors and/or other copyright owners and it is a condition of accessing publications that users recognise and abide by the legal requirements associated with these rights.

- Users may download and print one copy of any publication from the public portal for the purpose of private study or research.

- You may not further distribute the material or use it for any profit-making activity or commercial gain

- You may freely distribute the URL identifying the publication in the public portal.

If the publication is distributed under the terms of Article 25fa of the Dutch Copyright Act, indicated by the "Taverne" license above, please follow below link for the End User Agreement:

www.tue.nl/taverne

Take down policy

If you believe that this document breaches copyright please contact us at:

openaccess@tue.nl

providing details and we will investigate your claim. 


\title{
QUANTITATIVE ANALYSIS OF BONE REACTIONS TO RELATIVE MOTIONS AT IMPLANT-BONE INTERFACES*
}

\author{
H. WEINANS, † R. HUISKES† and H. J. GroOTENBOER $\ddagger$ \\ $\dagger$ University of Nijmegen, Institute of Orthopedics, Biomechanics Section, P.O. Box 9101, 6500 HB \\ Nijmegen, The Netherlands; and + Department of Biomedical Engineering, Faculty of Mechanical \\ Engineering, University of Twente, The Netherlands
}

\begin{abstract}
Connective soft tissues at the interface between implants and bone, such as in human joint replacements, can endanger the stability of the implant fixation. The potential of an implant to generate interface bone resorption and form soft tissue depends on many variables, including mechanical ones. These mechanical factors can be expressed in terms of relative motions between bone and implant at the interface or deformation of the interfacial material.

The purpose of this investigation was to determine if interface debonding and subsequent relative interface motions can be responsible for interface degradation and soft tissue interposition as seen in experiments and clinical results. A finite element computer program was augmented with a mathematical description of interface debonding, dependent on interface stress criteria, and soft tissue interface interposition, dependent on relative interface motions. Three simplified models of orthopaedic. implants were constructed: a cortical bone screw for fracture fixation plates, a femoral resurfacing prosthesis and a straight stem model, cemented in a bone. The predicted computer configurations were compared with clinical observations. The computer results showed how interface disruption and fibrous tissue interposition interrelate and possibly enhance each other, whereby a progressive development of the soft tissue layer can occur.

Around the cortical bone screw, the predicted resorption patterns were relatively large directly under the screw head and showed a pivot point in the opposite cortex. The resurfacing cup model predicted some fibrous tissue formation under the medial and lateral cup rim, whereby the medial layer developed first because of higher initial interface stresses. The straight stem model predicted initial interface failure at the proximal parts. After proximal resorption and fibrous tissue interposition, the medial interface was completely disrupted and developed an interface layer. The distal and mid lateral side maintained within the strength criterion.

Although the applied models were relatively simple, the results showed reasonable qualitative agreement with resorption patterns found in clinical studies concerning bone screws and the resurfacing cup. The hypothesis that interface debonding and subsequent relative (micro)motions could be responsible for bone resorption and fibrous tissue propagation is thereby sustained by the results.
\end{abstract}

\section{INTRODUCTION}

The development of fibrous tissues between implant and bone is an important determinant for clinical loosening of orthopaedic implants. In many cases mechanical factors are assumed to be involved in the driving mechanisms of this process (Perren and Rahn, 1980; Ling, 1986; Brunski et al., 1979; Brunski, 1987; Eftekar, 1985; Huiskes et al., 1990; Pizzoferrato et al., 1991). The problem can be described as a biological resorption process of the bone facing the implant, sometimes after many years of successful functioning. This process can be considered as a replacement of interface bone by a soft tissue layer which can easily deform under compression and is not capable of transmitting shear and tensile stresses. In some cases the situation remains stable for a long period of time (Brunski et al., 1979; Kozinn et al., 1986), but in many cases the process is a progressive one and an extensive

Received 4. September 1991; accepted for publication 24 Tarch 1993.

* Partly presented at the 34th Annual Meeting of the Orthopaedic Research Society, January 1988, Atlanta, Georgia radiolucent line around the implant can then be observed on a radiograph (Gruen et al., 1979; Strens, 1986).

Brunski et al. (1979) studied tissue-implant interfaces in functional (loaded) and nonfunctional (unloaded) endosseous dental implants. They found fibrous tissue layers around all functional implants and direct or nearly direct bone contact around the nonfunctional ones. They assumed that relative motions between implant and bone early after impiantation cause the fibrous tissue formation, due to repetitive loading of the implant. The same was suggested by Perren and Rahn (1980) and Perren (1983), who reported the development of a fibrous tissue encapsulation around screws used for fracture fixation plates. Their results showed a regular pattern of resorption around the load-bearing screws, which seemed to be related to the amount of relative motion between screw and cortical bone. Similar observations were reported earlier by Uhthoff and Germaine (1977), who described reversible fibrous tissue encapsulation dependent on the motion of the screw. Søballe et al. (1990) studied the effects of micromovement on bony ingrowth into titanium and hydroxylapatite-coated implants. Both groups developed 
a fibrous membrane, although the type of the connective tissue in the two cases was different. Bony ingrowth without fibrous tissue development was found when the implants did not move with respect to the bone.

All above-mentioned experimental studies refer to fibrous tissue formation early after implantation. It is assumed that this process is affected by a repair mechanism which usually results in the formation of (scar) fibrous tissue (Spector, 1988). Perren (1983), however, postulated that it is possible that long-term aseptic loosening is the result of the same mechanism. Once an implant is not mechanically bonded to the surrounding bone, for whatever reason, it can move with respect to the bone (micromotion). This repetitive micromotion can then subsequently lead to soft tissue formation between implant and bone, which finally results in a clinically loose implant. Similar hypotheses were also proposed by Eftekar et al. (1985), Ling (1986) and Pizzoferrato et al. (1991).

Strens (1986) studied the failure mechanism of femoral resurfacing prostheses in material retrieved from 28 revised cases. The resorption patterns showed a rather consistent configuration, with thick fibrous layers under the medial and lateral sides of the cup rim. Huiskes et al. (1990) showed that the concept of this design is such that (micro)motions, in the sense of displacements of the cup relative to the bone during repetitive loading, will progressively increase after mechanical disruption of the bone-implant contact areas under the lateral and medial side of the cup rim.

Several stress- or strain-related adaptive mechanisms for bone were proposed in the literature. Pauwels (1965) assumed that high compression leads to bone tissue degradation. Carter (1987) proposed that tissue differentiation depends on the magnitudes of the hydrostatic and deviatoric components of the stress tensor. In this theory it was assumed that a combination of high shear and/or hydrostatic tensile stress will encourage fibrous tissue formation. Carter (1987) hypothesized that the latter may be responsible for a stable fibrous membrane around orthopaedic implants. Cowin (1990) argued that this hypothesis needs a correction, since for anisotropic materials like bone, cartilage and birous tissue, the hydrostatic and deviatoric stress components are coupled.

In the present study it is hypothesized that relative (micro)motions (displacements) at the interface between implant and bone are responsible for bone resorption and fibrous tissue interposition around implants in the long term, following the ideas of Perren (1983). This is, in fact, an explanation for aseptic loosening. It is assumed that aseptic loosening starts with the disruption of the bond between a well-fixed implant and the surrounding bone, because of a repetitive excessive interface loading. This results in (micro)motion between implant and bone, which in turn triggers fibrous tissue formation (Eftekar et al., 1985; Ling, 1986; Pizzoferrato et al., 1991). The aim of this study is to find out if the development of a fibrous tissue and its usually nonuniform proliferation can be explained exclusively by this hypothesis. For this purpose a method is developed whereby the amount of bone resorption and the relative motions can be interrelated quantitatively. The approach uses the finite element method (FEM) integrated with simulation models, whereby the fibrous tissue growth is represented in an iterative feedback process, similar to those developed, for studying and predicting adaptive bone remodeling phenomena (Carter, 1987; Huiskes et al., 1990).

\section{METHODS}

A hypothetical scheme of gradual' interface disruption and subsequent bone resorption is shown in Fig. 1. The initiator of the process is interface disruption, shown in the upper loop of Fig. 1. An implant-bone configuration can be characterized mechanically by its geometry, material properties and interface (bonding) conditions between the different components. Loading of such a configuration generates stresses at the interfaces between implant and bone. When the interface stresses exceed the strength of the bonding, interface disruption or debonding will occur locally. The interface conditions then change and a new stress distribution is obtained at the interface. At the locations where interface disruption occurred, the two debonded materials can now move relative to each other. We hypothesize that if these relative motions exceed a certain threshold level, they will affect the osteoblastic and/or osteoclastic activities of the adjacent bone and provoke interface-bone resorption. The resorbed bone is then replaced by a soft fibrous tissue; hence, the interface conditions change. The latter process is governed by the lower loop in Fig. 1.

In order to obtain quantitative predictions of these processes, mathematical formulations of the two feedback control systems are required. For the disruption or debonding loop a strength criterion as presented by Stone et al. (1983) was used. They determined a multiaxial (Hoffmann's) failure criterion for cancellous bone, which can be described by an ellipsoid for three-dimensional or an ellipse for two-dimensional cases. We assume a similar debonding criterion for the implant/bone interface. Figure 2 shows an ellipse describing the interface strength of the implant/bone

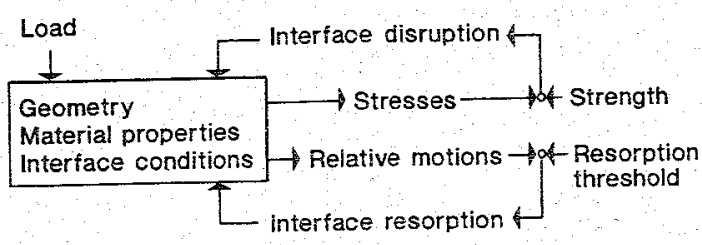

Fig. 1. The hypothetical scheme of the aseptic loosening process, whereby the interface bonding characteristics and the thickness of the intermediate fibrous tissue layer can successively change. 


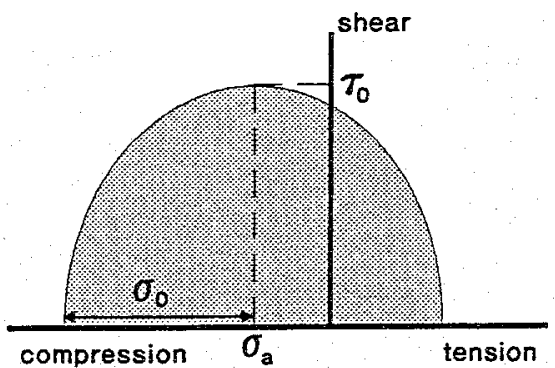

Fig. 2. Failure criterion for the implant-bone interface Within the shaded area the interface bond stays intact.

interface. A combination of interface normal and shear stress values outside this ellipse provokes a failure of the bond. Hence, in mathematical terms, interface failure will occur if

$$
\left(\frac{\sigma-\sigma_{\mathrm{a}}}{\sigma_{0}}\right)^{2}+\left(\frac{\tau}{\tau_{0}}\right)^{2}>1
$$

with $\sigma$ and $\tau$ the actual normal and shear stresses, respectively, and $\sigma_{0}, \sigma_{\mathrm{a}}$ and $\tau_{0}$ constants as shown in Fig. 2.

The resorption feedback loop is governed by a hypothetical mathematical expression, relating the rate of local bone removal to the local relative tangential and perpendicular (micro)motions at the interface, relative to the thickness of the intermediate fibrous tissue layer. Although it was often suggested that such a relationship does exist, a quantitative relationship based on experiments cannot be found in the literature. We propose a relationship whereby the growth rate $\mathrm{d} b / \mathrm{d} t$ of the fibrous interface layer, with thickness $b$ (Fig. 3), depends on relative motions expressed in terms of the strains within this layer, according to

$$
\frac{\mathrm{d} b}{\mathrm{~d} t}=c_{i j} \varepsilon_{i j}
$$

where $\mathrm{d} b / \mathrm{d} t$ is the rate of bone resorption perpendicular to the interface, $\varepsilon_{i j}$ the actual strain tensor in the soft tissue layer and $c_{i j}$ a matrix of constants. The strains in the fibrous layer may become extremely large, relative to physiological bone strains, since the fibrous tissue layer is extremely flexible (Hori and Lewis, 1982; Weinans et al., 1990). The resorption threshold as proposed in Fig. 1 is not used or can be regarded as taken to be zero in this approach. In the two-dimensional model presently applied (Fig. 3), a local coordinate system is defined, with the $n$ (ormal)-axis perpendicular to the implant contour, and the $p$ (arrallel)-axis tangential to the contour. Accordingly, we define the direct strains $\varepsilon_{n}$ and $\varepsilon_{p}$ in the layer, and the shear strains, $\varepsilon_{n p}=\varepsilon_{p n}$. The out-of-plane strain is assumed to be zero (plane-strain state). Locally, the (elastic) displacements of implant relative to bone are denoted by $\Delta u_{n}$ perpendicular and $\Delta u_{p}$ tangential to the interface. The amount of bone resorbed and replaced by fibrous tissue during time period $\Delta t$ is $\Delta b$.

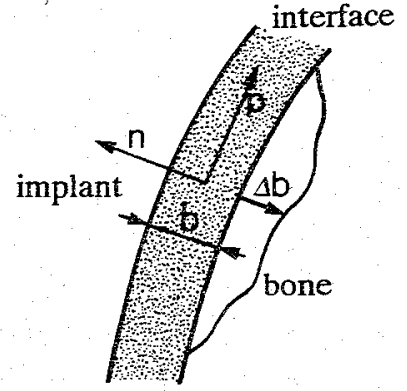

Fig. 3. Interface layer with implant at the left and bone at the right. The coordinates $n-p$ are taken parallel and normal to the interface. The thickness and growth of the interface are expressed by $b$ and $\Delta b$, respectively.

We use the approximations $\varepsilon_{n}=\Delta u_{n} / b$, $\varepsilon_{n p}=\varepsilon_{p n}=\Delta u_{p} / b, \varepsilon_{p}=-v \varepsilon_{n}=-v \Delta u_{n} / b$, where $v$ is Poisson's ratio. These approximations are reasonable when the interface layer is relatively thin (Weinans $e t$ al., 1990). After forward Euler integration of equation (2) and substitution of $\Delta u_{p}$ and $\Delta u_{n}$ for the strain components, we may write

$$
\begin{aligned}
\Delta b & =\left(c_{n} \varepsilon_{n}+c_{p} \varepsilon_{p}+c_{n p} \varepsilon_{n p}+c_{p n} \varepsilon_{p n}\right) \Delta t \\
& =\left(c^{\prime} \frac{\Delta u_{n}}{b}+c^{\prime \prime} \frac{\Delta u_{p}}{b}\right) \Delta t,
\end{aligned}
$$

with $b$ the thickness of the fibrous layer and $\Delta t$ the time step. Since no quantitative experimental information is available concerning this assumed relationship, we have chosen $1.0 \mathrm{~mm} /$ time-unit for the constants $c^{\prime}$ and $c^{\prime \prime}$, which can be considered as preliminary values for the hypothesis.

Equations (1) and (3) were incorporated into the FEM code (Marc Analysis Corporation, Palo Alto, CA). The fibrous tissue layer was modeled as a nonlinear elastic foundation. Special elements, introduced earlier, described the nonlinear contact conditions and the nonlinear material properties of the fibrous tissue layer (Weinans et al., 1990). The resistance of the layer to tension and shear is assumed to be negligible (Hori and Lewis, 1982). For compression we assume (Fig. 4)

$$
\left|\sigma_{n}\right|=25.0\left(\frac{1}{\left(1-\left|\varepsilon_{n}\right|\right)^{4}}-1\right), \quad-1<\varepsilon_{n} \leqslant 0
$$

hence, the initial stiffness ( $d \sigma / \mathrm{d} \varepsilon$ for $\varepsilon=0$ ) is $100 \mathrm{MPa}$ (Weinans et al., 1990). The initial thickness of the layer is taken as one micron, representing direct boneimplant contact. Before debonding of the interface, the layer is assumed to be extremely stiff in all directions, simulating complete bonding. The nodal forces transferred by the interface layer, and calculated in the FEM analysis, are expressed in terms of normal stress, $\sigma_{n}$, and shear stress, $\tau_{p}$ (Weinans et al., 1990). These stress values are used to control the failure mechanism of the interface bond according to equation (1). A disruption of the interface bond changes the bonding 


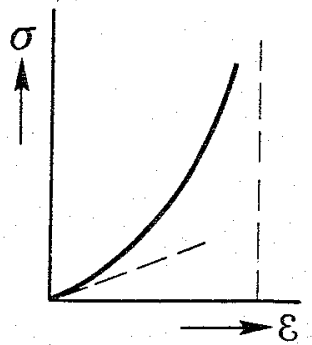

Fig. 4. Nonlinear material properties for the intermediate layer in compression.

conditions from linear to nonlinear contact (only compression forces to be transmitted) and nonlinear material properties as assumed for a soft tissue layer of one micron thickness [equation (4)]. Depending upon the amount of relative displacements [equation (3)], the nodal points of the bone, facing the interface, are relocated in the direction of the bone, perpendicular to the interface (Fig. 3). This implies that the soft interface layer grows and the overall stiffness of the layer in compression reduces. The relocation of the bone interface nodes also changes the geometry of the bone. In the next iterative step, new interface stresses and relative displacements are determined and subsequent bone resorption and fibrous tissue development may occur. The process is solved in an iterative procedure, using constant time steps, as shown in Fig. 5. In each iterative step, the nonlinear contact and material conditions of the soft tissue layer are solved first in an iterative Newton-Raphson subprocedure. The second iterative subprocedure concerns the failure criterion, based on Fig. 2 and equation (1). When this procedure is solved, the third procedure, governing the resorption rule of equation (3), is applied. The simulation process continues until it stabilizes or proliferation to clinical loosening is evident.

The method was used in three simplified boneimplant configurations, using two-dimensional finite element models with isoparametric, four-node, plane-stress elements. The first model [Fig. 6(a)] simulates a cortical-bone screw for fracture-fixation plates, similar to the configuration studied by Perren (1983) and Perren and Rahn (1980). The constants $\sigma_{0}$, $\sigma_{\mathrm{a}}$, and $\tau_{0}$, used in the failure criterion governed by Fig. 2 and equation (1), were all taken as zero, representing an unbounded interface connection from the beginning, transmitting compressive stress only. A side plate, connecting the periosteal sides of the cortical bone, was used to account for the threedimensional integrity of the structure. The second model concerns the fixation of a femoral resurfacing prosthesis [Fig. 6(b)], with spanning elements to model the three-dimensional rigidity of the cup (Huiskes et al., 1990). The parameters in the failure criterion were chosen in this case as $\sigma_{0}=2.0 \mathrm{MPa}$, $\sigma_{\mathrm{a}}=1.0 \mathrm{MPa}$ and $\tau_{0}=2.0 \mathrm{MPa}$. The latter two models

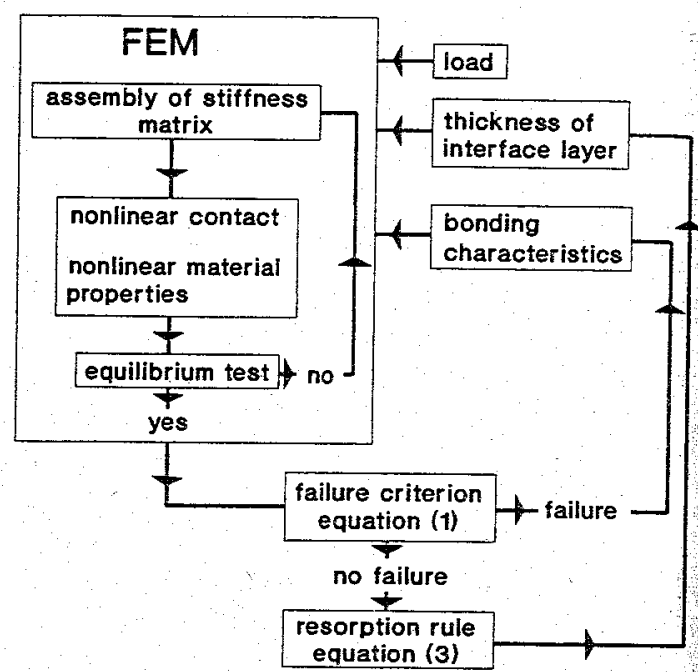

Fig. 5. The chain of events in the iterative computer procedure. The first iterative procedure solves the nonlinear contact conditions and the nonlinear material properties (Weinans et al., 1990). A second iterative loop represents the propagation of debonding of the interface (Fig. 2) and finally, the third loop describes the layer formation, whereby the geometry of the finite element mesh is updated in each iteration. When the third feedback loop slows down, a new 'stable' end configuration is obtained.

are compared with experimental configurations, as mentioned in the Introduction.

The third model consists of a straight stem, cemented into a straight bone and loaded in pure bending [Fig. 6(c)], as a simple model of intramedullary fixation as in the femoral component of total hip arthroplasty. Again a side plate was used to account for out-of-plane cortical bone (Huiskes, 1980). The constants used in the failure criterion were now taken as $\sigma_{0}=5.5 \mathrm{MPz}, \sigma_{\mathrm{a}}=2.5 \mathrm{MPa}$ and $\tau_{0}=8.0 \mathrm{MPa}$, assuming a stronger bond between cement with intramedullary cancellous bone as compared to the bone of the femoral head in the previous example. The cement-bone bonding values were selected rather arbitrarily, but similar to literature values in order of magnitude (Kölbel et al., 1978; Krause et al., 1982). The loading conditions in the three examples are indicated in Fig. 6 and should be considered as a repetitive loading variation between zero and the applied load.

\section{RESULTS}

As could be expected, the predicted amount of interface resorption was highly dependent on the actual values chosen for the parameters in the interface disruption and resorption rules [equations (1) and (3)], and the external loads applied on the implants in the models. In the present analyses, these parameters were selected in such a way that the end configurations were found in a realistic range, and 

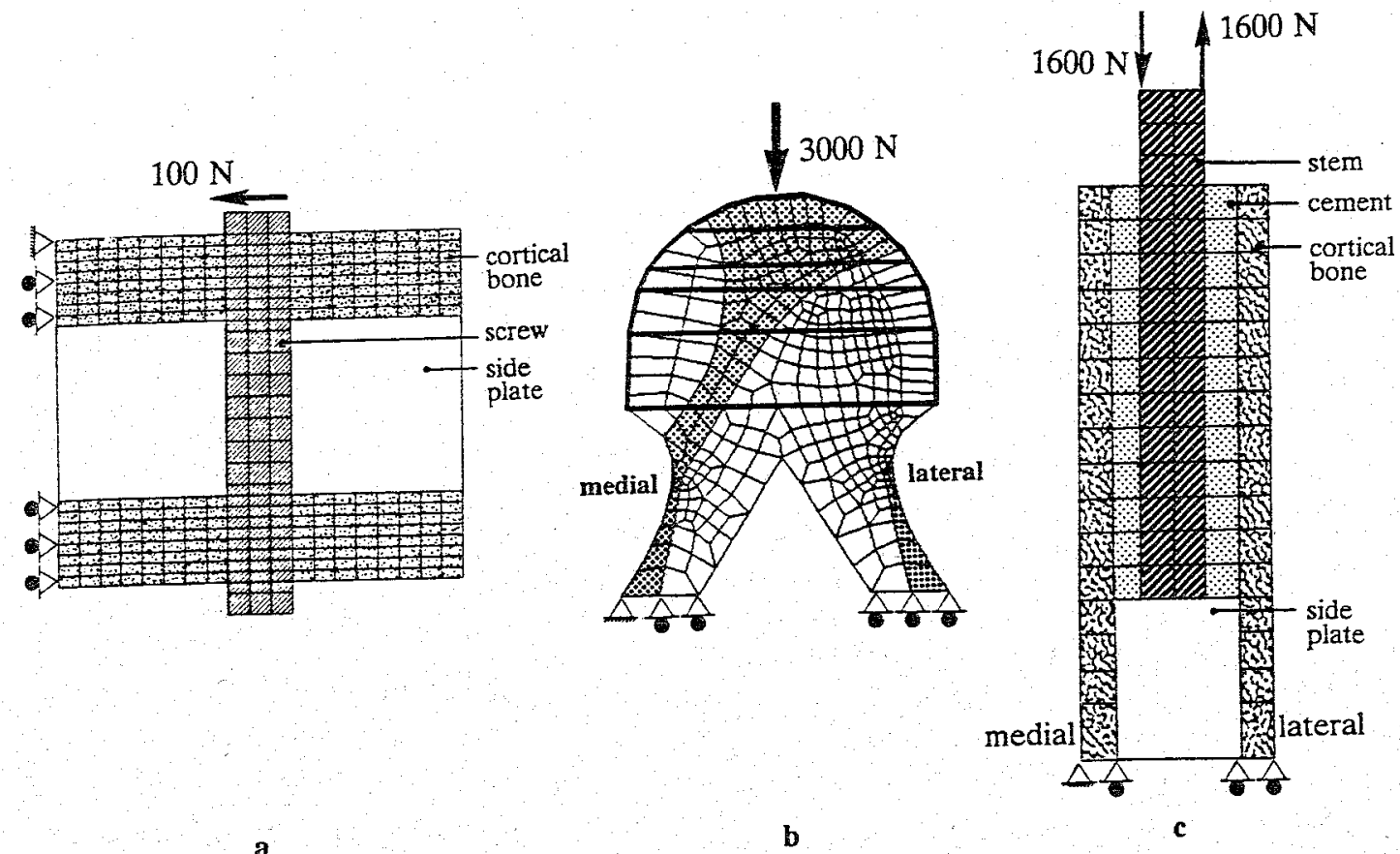

a

Fig. 6. (a) Finite element model of a screw fixed in the bone cortices. The elastic moduli are taken at $200,000 \mathrm{MPa}$ for the screw and 17,000 MPa for the cortical bone of front and side plates. (b) Finite element model of a femur head with a resurfacing cup. The cup was made out of beam elements, indicated by the thick lines (Huiskes et al, 1990). Three different moduli were used in the model: 17,000 MPa for the cortical bone in the medial and lateral femoral neck (dark shaded), $550 \mathrm{MPa}$ for the cancellous bone in the center of the head (light shaded) and $400 \mathrm{MPa}$ for the remaining cancellous bone (white). (c) Simple finite element model of a cemented stem in the femoral medullary canal. The elastic moduli were taken at $17,000 \mathrm{MPa}$ for the cortical bone, $3000 \mathrm{MPa}$ for the bone cement and $200,000 \mathrm{MPa}$ for the stem.

reasonable similarity with experimental data could be obtained.

\section{Cortical screw model}

Bone resorption and subsequent fibrous tissue deposition around the screw was found to be quite severe: The resorption patterns were more extensive in the cortex directly under the screw head. A kind of pivot point developed in the opposite cortex, indicated in Fig. 7(a). These result are very similar to experimental ones, of which a typical example is shown in Fig. 7(b) (Perren, 1983).

It should be noted that the interface is assumed to be unbonded. Hence, in the initial state all interface nodal points of the implant can move with respect to the bone. Thus, resorption can take place along the whole interface, directly from the first iteration. After ten iterative steps in the ensuing resorption procedure, proliferation seemed evident and the simulation was terminated. Hence, Fig. 7(a) does not represent a converged end configuration.

\section{Resurfacing cup model}

This simulation shows that debonding and subsequent bone resorption and fibrous tissue deposition can strongly affect and amplify each other. They are, in fact, interrelated by the feedback system as pres- ented in Fig. 5. The loosening process of the cup started under the medial cup rim, where the interface stresses were maximal, as shown in Fig. 8(a). The debonding and resorption processes then continued, amplifying each other, and proliferated until the simulation was terminated after 12 increments. The final shear and normal stress patterns at the interface are close to zero under the loose medial and lateral cup rim and having peak values at the rim of the bonded area as shown in Fig. $8(\mathrm{~b})$. The predicted resorption patterns of the simulation showed a medial resorption which was more extensive than the lateral one [Fig. 9(a)]. This is similar to what was found in a clinical retrieval study of such an implant by Strens (1986). The retrieved specimen, as shown in Fig. 9(b), can be regarded as a typical configuration for the clinical results as found in 28 resuriacing-cup revision cases (Strens, 1986). The medial resorption was more extensive than the lateral one, similar to what is found in the computer simulation.

\section{Straight stem model}

The simplified straight stem version of an intramedullary fixation shows that, at least in theory, an already started process of debonding and fibrous tissue interposition may stabilize under certain conditions. In the initial configuration the interface stress 


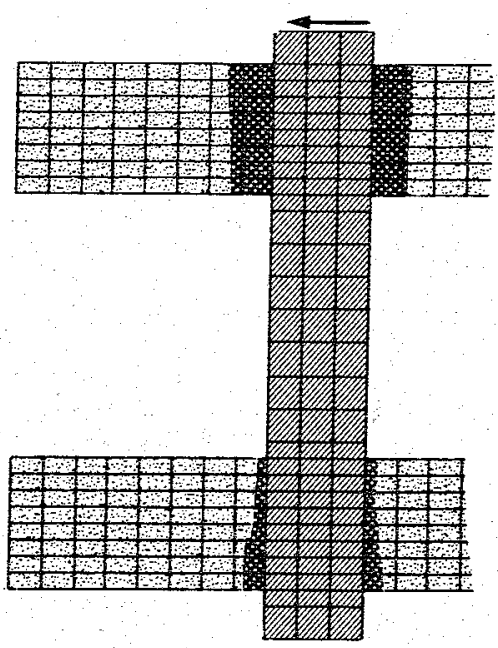

a

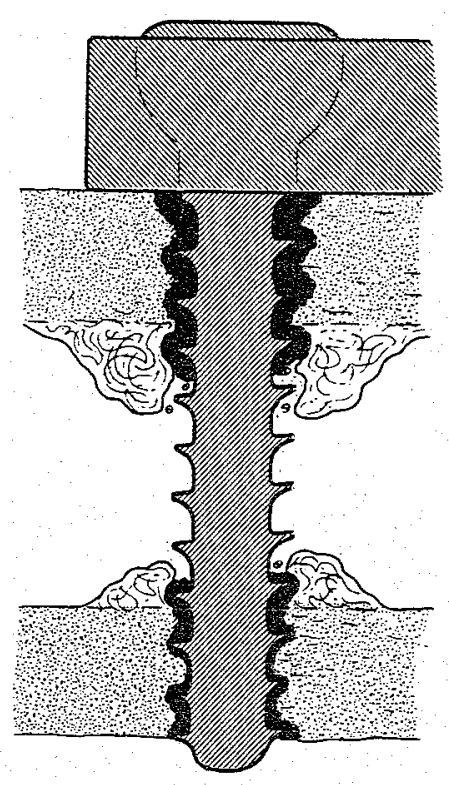

b

Fig. 7. (a) Result after the tenth iteration of the resorption process around the bone screw. The resorbed bone is indicated in black. The simulation results in a pivot point in the cortex opposite to the screw head. (b) The general resorption pattern around bone screw fixations [adapted from Perren (1983)], with fibrous tissue indicated in black. According to Perren (1983), this pattern is directly related to the amount of motion between screw and bone.

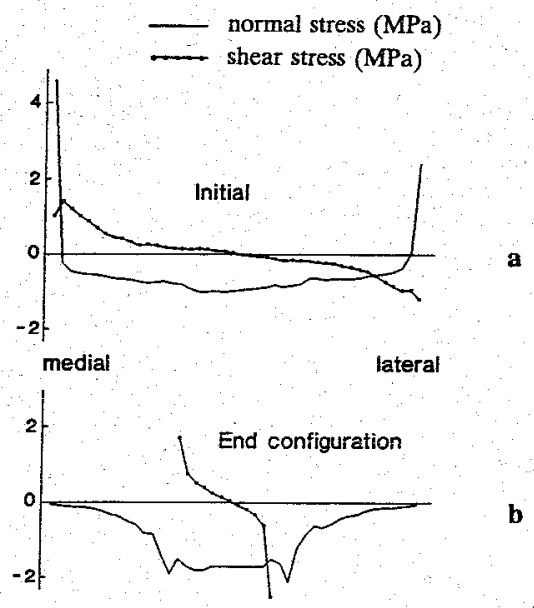

Fig. 8. Interface stresses during two stages of the disruption and resorption process at the interface between resurfacing cup and bone in the initial situation (a) and after debonding and soft tissue interposition (b). At the medial and lateral sides the interface starts to disrupt and in the end configuration only the central part of the implant transfers the load.

peaks were found at the proximal and distal ends, which is a typical pattern for a stem in a proximal femur (Huiskes, 1980; Huiskes et al., 1990). The interface stresses at the medial bone cement interfaces as found during the iterative procedure of the straight stem simulation change successively after the ongoing debonding and fibrous tissue proliferation procedure, as shown in Fig. 10(a) -(c), for the initial, transient and end configuration. At the proximal and distal parts of the medial interface and at the proximal lateral interface, debonding occurred, whereby the interface stress patterns changed [Fig. 10(b)]. Relative motions now occurred at the disrupted parts and subsequently bone resorption and more debonding followed, until the process stabilized. In the end configuration a kind of pivot point was created at the mid lateral area, where the interface stresses stayed within the failure boundary [Fig. 10(c)]. Resorption took place predominantly at the proximal parts of the interface, as demonstrated in Fig. 10(d).

\section{DISCUSSION}

This siudy is a first attempt to relate quantitatively relative (micro)motions to long-term connectivetissue interposition. For short-term experiments the existence of such a relationship in the direct postoperative period has been shown in the literature many times (Uhthoff and Germaine, 1977; Perren and Rahn, 1980; Brunski et al., 1979; Søballe et al., 1990, 1991). In the long-term the relationship is difficult to demonstrate in an experiment; however, it is often assumed that interface debonding and subsequent (micro)motion causes fibrous tissue interposition and 
(a)

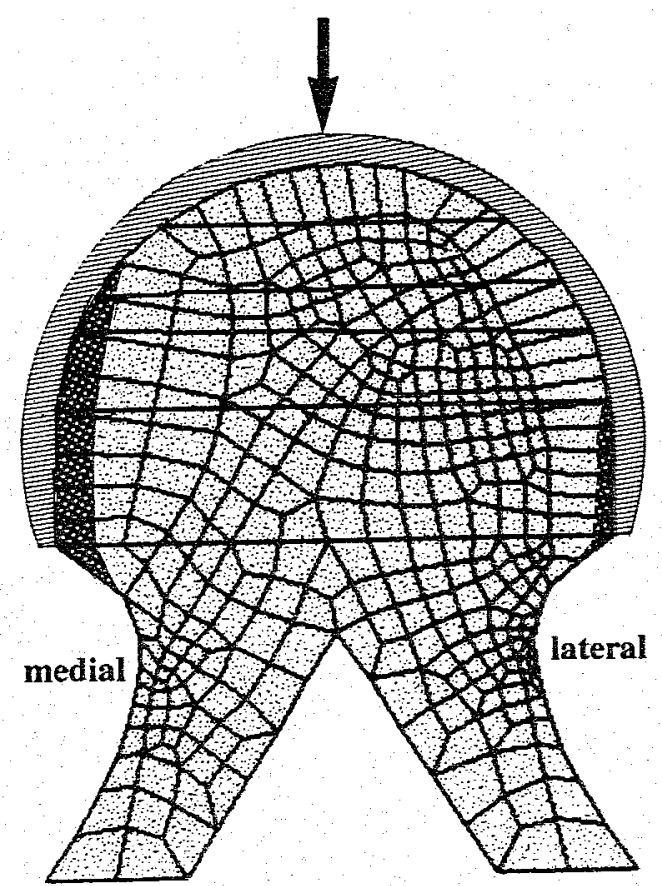

(b)

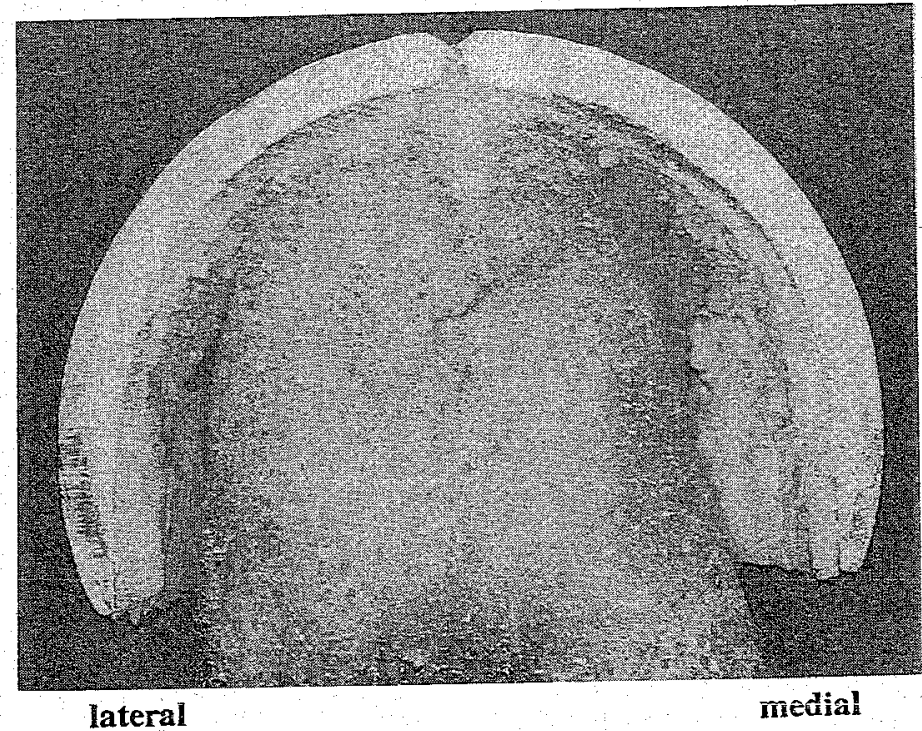

Fig. 9. (a) The resorption patterns under the cup after the 12 th iteration in the resorption feedback loop, as predicted by the simulation model. At the medial side the soft tissue formation is more severe because the implant started to disrupt at this side [Fig. 8(a)], and the relative motions are as a consequence more substantial at this side. (b) A representative configuration of a retrieved resurfacing cup [adapted from Strens (1986)], with the most severe resorption under the medial cup rim. 


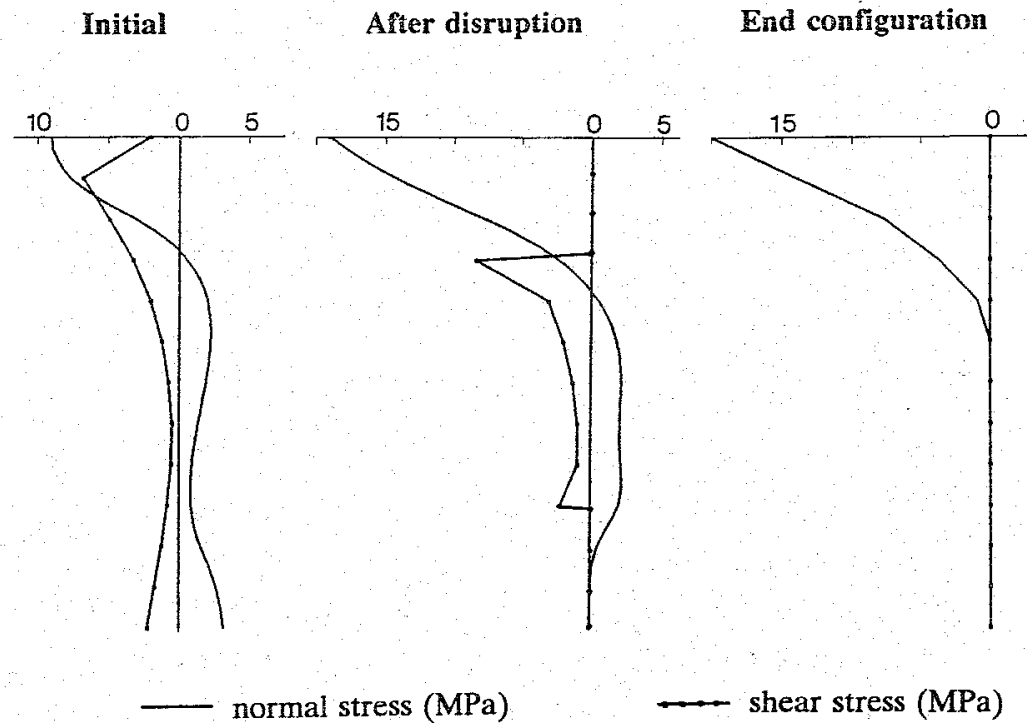

a

b

c

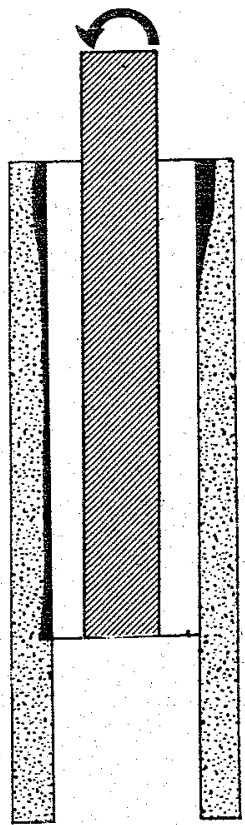

d

Fig. 10. (a)-(c). Interface stresses at the medial side of the cement-bone interface as successively found in the different stages of the loosening process. In the end configuration the lateral distal interface is not disrupted because the interface stresses stay within the strength criterion. (d) End configuration of the disruption and resorption process at the interface of the straight stem-bone model. The nonuniform resorbed interface area filled with fibrous tissue is indicated in black.

aseptic loosening (Eftekar et al., 1985; Ling, 1986; Pizzoferrato et al., 1991).

There can be little doubt that the resorption of interface bone and the subsequent generation of fibrous tissue is also stimulated by wear particles (Willert et al., 1974; Pizzoferrato et al., 1991; Harris, 1992). For cemented implants, it is likely that excessive heat generation in acrylic cement during polymerization plays a role (Feith, 1975; Huiskes, 1980). However, mechanical factors are often assumed to be involved. The results of the present analyses show that interface resorptive phenomena can be incorporated in FEM models, enabling a closer link between mechanical analyses and histomorphological and clinical investigations. The present findings show that interface stress patterns and relative motions will change drastically the loosening process of a prosthesis, whereby a progressive enhancement of the process can easily develop. There is qualitative agreement between the predicted resorption patterns and the animal experimental configurations as described by Perren and Rahn (1980) for the screw, and Strens (1986) for the retrieved clinical specimens of resurfacing cups. This supports the hypothesis that the loosening process of these implants and the subsequent proliferation of a nonuniform interface layer can be interpreted by a scheme such as that proposed in Fig. 1. A similar scheme (including also more de- tailed biological information) was proposed earlier by Eftekar et al. (1985):

In a quantitative sense it is difficult to relate the present results with experimental findings. The range of micromotions tested in experimental studies varies in size and directionality. Søballe et al. $(1990,1991)$ used a range of $150-500 \mu \mathrm{m}$ relative motion in the longitudinal direction between a porous coated experimental implant and bone. Schneider et al. (1989) showed in a cadaver study that repetitive elastic slip between bone and a cementless stem occurs, thereby generating normal relative interface motions of about $100-300 \mu \mathrm{m}$ in the direction normal to the bone. In comparison, the straight stem model showed $220 \mu \mathrm{m}$ maximal relative displacements in the direction normal to the bone and $140 \mu \mathrm{m}$ in the longitudinal direction, both found at the proximal laterai side. In the screw model this was, respectively, $272 \mu \mathrm{m}$ in the normal and $25 \mu \mathrm{m}$ in the longitudinal direction (proximally). The resurfacing cup model gave $22 \mu \mathrm{m}$ (normal) and $82 \mu \mathrm{m}$ (longitudinal) as maximal relative displacements.

It is evident that the FEM models applied in this study are rather simplified with respect to the actual situation. The models are two-dimensional (although side plates or spanning elements were used to represent some of the three-dimensional characteristics) and include the most important aspects of the real struc- 
ture only. Several physical phenomena are not accounted for in the models; for instance, the effects of interface irregularities, the presence of fluid in the soft layers and the voids at the interface area, and fatigue failure phenomena of the interface. Furthermore, the debonding criterion [equation (1)] and the resorption rule [equation(3)] are hypothetical entities only. Prediction of crack propagation realistically in a quantitative sense is a difficult numerical problem, in particular for a complicated interface as the one between implant and cement. From a mechanicalanalysis point of view, the tip of the fracture should be considered as a singularity and the stress values are, therefore, dependent on the size, shape and type of the element (Carey and Ogden, 1983). Thus, for a precise (quantitative) description of crack propagation, more sophisticated methods must be used (Lewis, 1988; Santare et al., 1987).

An interesting finding from the present examples is that it shows how interface loosening and bone resorption may interact, as hypothezised earlier by Eftekar et al. (1985). Interface debonding at a particular location may lead to an increase of the interface stresses and relative motions at another location. Depending upon the precise configuration (geometry, material properties of the components and interface characteristics), the interface disrupts completely or incompletely. Hence, the process of soft interface proliferation may or may not occur. The capacity of an implant to stabilize after some loosening ('secondary stability') is, of course, of great clinical importance. This stabilization could become possible when the interface stress patterns are not extremely sensitive for some initial debonding (in the sense that they would not increase after some debonding and some fibrous tissue interposition). Another stabilization mechanism one could imagine, though this is not so obvious from the present findings, is that the strains in the fibrous layer decrease when the fibrous layer grows. This is possible only when the amount of displacement $[\Delta U$, equation (3) $]$ is not progressively dependent on the thickness of the layer $[b$, equation (3)], so that $\Delta U / b$ decreases when $b$ increases.

Probably, the most important parameter to prevent initial mechanical interface failure ('primary stability') is the quality of the interface bond. This factor is represented in the simulation models by the debonding criterion, which is dependent, in reality, on the precision of the surgical procedure, the quality of the bone stock and the penetration of the bone cement in case of a cemented implant (Krause et al., 1982) or the amount of bone ingrowth into uncemented implants. Assuming that these factors are all optimized relative to bonding strength, the next step for the optimization of survival rates is to improve the 'secondary stability'. In other words, to optimize a design such that it is relatively insensitive for some interface debonding and fibrous tissue development. Implant material properties and geometry can be modified to prevent ongoing interface debonding after some debonding and fibrous tissue interposition has occurred, or to prevent excessive relative motions occurring, once interface debonding is a fact. For press-fitted implants, where no direct bond between implant and bone is created, the latter design feature is extremely important (Walker and Robertson, 1990). A simulation method such as that presented in this study can eventually develop into a powerful tool for prosthetic design and evaluation analyses and, in this sense, benefit orthopaedic fixation techniques.

The present investigation should be considered as a first study to see whether interface disruption and relative motions could be responsible for the loosening processes observed around many orthopaedic implants. This hypothesis is sustained by the results. It is possible that, indeed, failure by high interface stresses and subsequent relative motions may together act as driving forces for (aseptic) loosening of implants.

\section{REFERENCES}

Brunski, J. B. (1987) The influence of force, motion and related quantities on the response of bone to implants. In Non-cemented Total Hip Arthroplasty: The Bone Interface (Edited by Fitzgerald, R. H.) pp. 7-21. Raven Press, New York.

Brunski, J. B., Aquilante, F. M., Pollack, S. R., Korostoff, E. and Trachtenberg, D. I. (1979) The influence of functional use of endosseous dental implants on the tissue-implant interface. I. Histological aspects. J. Dental Res. 58, 1953-1969.

Carey, G. F. and Ogden, J. T. (1983) Finite Elements: A Second Course. Prentice-Hall, Englewood Clifs, NJ.

Carter, D. R. (1987) Mechanical loading history and skeletal biology. $J$. Biomechanics 20, 1095-1110.

Cowin (1990) Deviatoric and hydrostatic mode interaction in hard and soft tissue. $J$. Biomechanics 23, 11-14.

Draenert, K. (1981) Histomorphology of the bone-to-cement interface remodeling of the cortex and revascularization of the medullary canal in animal experiments. In The Hip (Edited by Salvati, E. A.), Proc. 9th Meeting of the Hip Soc., 1981, pp. 71-110. CV Mosby, St Louis.

Eftekar, N. S., Doty, S. B., Johnston, A. D. and Parisien, M. V. (1985) Prosthetic synovitis. In The Hip (Edited by Fitzgerald, R. H.), Proc. 13th Meeting of the Hip Soc., 1985, pp. 169-183. CV Mosby, St Louis.

Feith, R. (1975) Side effects of acrylic cement, implanted into bone. Acta orthop. scand (suppl.) 161.

Goldring, S. R., Schiller, A. L., Roelke, M., Rourke, C. M., O'Neill, D. A. and Harris, W. H. (1983) The synoviallike membrane at the bone-cement interface in loose total hip replacements and its proposed role in bone lysis. J. Bone Jt Surg. 65A, 575-584.

Gruen, T. A., McNeice, G. M. and Amstutz, M. D. (1979) Modes of failure of cemented stem-type femoral components. Clin. Orthop. 141, 17-27.

Harris, W. H. (1992) The first 32 years of total hip arthroplasty: one surgeon's perspective. Clin. Orthop. Rel. Res. 274, 6-11.

Hori, R. Y. (1981) Investigation of the bone-prosthesis interface following total joint replacement. Ph.D. dissertation, North Western University, Chicago, IL.

Hori, R. Y. and Lewis, J. L. (1982) Mechanical properties of the fibrous tissue found at the bone-cement interface following total joint replacement. $J$. Biomater. Res. 16, 911-927.

Huiskes, R. (1980) Some fundamental aspects of human joint replacement. Acta orthop. scand. (suppl.) 185. 
Huiskes, R. and Nunamaker, D. (1984) Local stresses and bone adaption around orthopaedic implants. Calcif. Tissue Int. 36, S110-S117.

Huiskes, R. and Schouten, R. Y. (1980) The effect of interface loosening on the stress distribution in intramedullary fixated artificial joints. In Advances in Bioengineering (Edited by Mow, Van C.) pp. 213-217. ASME, New York.

Huiskes, R., Strens, P., Vroemen, W. and Slooff, T. J. (1990) Post-loosening mechanical behavior of femoral resurfacing prostheses. Clin. Mater. 6, 37-55.

Kölbel, R., Bergmann, G. and Boenick, U. (1978) Mechanical properties of the cement/bone bond. In Advances in Artificial Hip and Knee Joint Technology (Edited by Schaldach, $M$. and Hohmann, D.). Springer, Berlin.

Kozinn, S. C., Norman, A. J. and Bullough, P. G. (1986) The biologic interface between bone and cementless femoral endoprostheses. J. Arthroplasty 1, 249-259.

Krause, W. R., Krug, W., Eng, B. and Miller, J. (1982) Strength of cement-bone interface. Clin. Orthop. 163, 290-299.

Lewis, J. L. (1988) The mechanical state of bone-implant interface. In Non-cemented Total Hip Arthroplasty: The Bone Interface (Edited by Fitzgerald, R. H.) pp. 23-30. Raven Press, New York.

Ling, R. S. M. (1986) Observation on the fixation of implants to the bone skeleton. Clin. Orthop. 210, 80-96.

Pauwels, F. (1965) Gesammelte Abhandlungen zur Funktionellen Anatomie des Bewegungsapparates. Springer, Berlin. Translated as Biomechanics of the Locomotor Apparatus. Springer, Berlin, 1980.

Perren, S. M. (1983) Induktion der Knochenresorption bei Prothesenlockerung. In Die Zementlose Fixation von Hüftendoprothesen (Edited by Morcher, E.) pp. 38-40. Springer, Berlin.

Perren, S. M. and Rahn (1980) Biomechanics of fracture healing. Canad. J. Surg. 20, 228-231.

Pizzoferrato, A., Ciapetti, G., Stea, S. and Toni, A. (1991) Cellular events in the mechanisms of prosthesis loosening. Clin. Mater. 7, 51-81.

Santare, M. H., Keer, L. M. and Lewis, J. L. (1987) Cracks emanating from a fuid filled void loaded in compression: application to the bone-implant interface. $J$. Biomech. Engng 109, 55-59.
Schneider, E., Eulenburger, J., Steiner, W., Wyder, D., Friedman, R. J. and Perren, S. M. (1989) Experimental method for the in vitro testing of the initial stability of cementless hip prostheses. J. Biomechanics 22, 735-744.

Søballe, K., Hansen, E. S., Rasmussen, H. B., Jørgensen, P. $H$. and Bünger, C. (1990) Hydroxyapatite coating provides a stronger fibrous anchorage of implants with controlled micromotion. Trans. orth. Res. Soc., p. 206.

Søballe, K., Hansen, E. S., Rasmussen, H. B. and Bünger, C. (1991) Hydroxyapatite implant coating modifies membrane formation during unstable mechanical conditions. Trans. orth. Res. Soc., p. 35.

Spector, M. (1988) Current concepts of bone ingrowth and remodelling. In Non-Cemented Total Hip Arthroplasty: The Bone Interface (Edited by Fitzgerald, R. H.), pp. 69-85. Raven Press, New York.

Stauffer, R. N. (1982) Ten-year follow-up study of total hip replacement with particular reference to roentgenographic loosening of the components. J. Bone Jt Surg. 64A, 983-990.

Stone, J. L., Beaupré, G. S. and Hayes, W. C. (1983) Multiaxial strength characteristics of trabecular bone. J. Biomechanics 16, 743-752.

Strens, P. H. G. E. (1986) Analysis of implant failure in the Wagner resurfacing arthroplasty. Doctoral dissertation, University of Nijmegen.

Uhthoff, H. K. and Germaine, J. B. (1977) Reversal of tissue differentiation around screws in bone. Clin. Orthop. Rel. Res. 123, 148

Vanderby, R., Lewis, J. L. and Chapman, S. M. (1985) Biphasic modeling of fibrous tissue at the bone-prosthesis interface in total joints. In Trans. Winter Annual Meeting of the ASME (Edited by Langrana, N. A.) pp. 22-23.

Walker, P. S. and Robertson, D. D. (1990) The design and fabrication of cementless hip stems. Clin Orthop. Rel. Res. $235,25-34$.

Weinans, H., Huiskes, R. and Grootenboer, H. I. (1990) Trends of mechanical consequences and modeling of a fibrous membrane around femoral hip prostheses. J. Biomechanics 23, 991-1000.

Willert, H. G., Ludwig, J. and Semlitsch, M. (1974) Reaction of bone to methacrylate. J. Bone Jt Surg. 56A, 1368-1382. 